The Geneva Papers on Risk and Insurance, 18 (No. 67, April 1993), 144-157

\title{
Strategies and Techniques for Asset-Liability Management: an Overview
}

\author{
by Robert van der Meer and Meye Smink ${ }^{1}$
}

\section{Introduction}

In the past decade, both practitioners in the insurance industry and theoreticians have shown a renewed interest in Asset-Liability Management, most of this attention resulting from the turbulent interest rates climate in the early eighties. A great number of strategies has evolved, some of them simple, others using advanced theory from finance or actuarial science. Therefore it has become increasingly difficult to oversee and evaluate all these strategies. This article provides a short overview of a number of strategies and techniques. It discusses their main benefits and potential weaknesses and suggests evaluative criteria. Moreover, it provides guidance for further study. However, although many methods are covered, this article does not claim to be exhaustive.

The strategies and techniques analysed may be classified in three distinct groups: 1) static, 2) value driven, and 3) return driven. First, we make a distinction between techniques and strategies. Where the techniques are considered as being essentially static, the strategies require some set of decision making rules for behaviour ${ }^{2}$ and are explicitly dynamic. Moreover, we make a classification into dynamic strategies based on immunization principles - these strategies are essentially value driven - and dynamic strategies that are predominantly return driven. The strategies and techniques discussed are shown in Figure 1; for abbreviations refer to the main text.

Although multiscenario analysis and risk-return analysis could be treated as elements of these three distinct categories, they are treated separately here. This because multiscenario analysis, although static in nature, is typically designed for multiperiod decision making and risk-return analysis is a general framework and can be used for evaluation of techniques and strategies from all categories.

After discussion of the techniques and strategies, attention is paid to evaluative criteria for the differences between them. The article ends with conclusions and a summary.

\footnotetext{
${ }^{1}$ Robert van der Meer is a Member of the Executive Board and a Managing Director of AEGON N.V. and part-time Professor of Finance at the University of Groningen. Meye Smink is research-assistant at the University of Groningen and is working on his PhD-thesis on Asset-Liability Management for life-insurance companies.

${ }^{2}$ See e.g. Ansoff I. and McDonnell E.: Implanting Strategic Management, 2nd edition, Prentice Hall, 1990 .
} 
Figure 1:

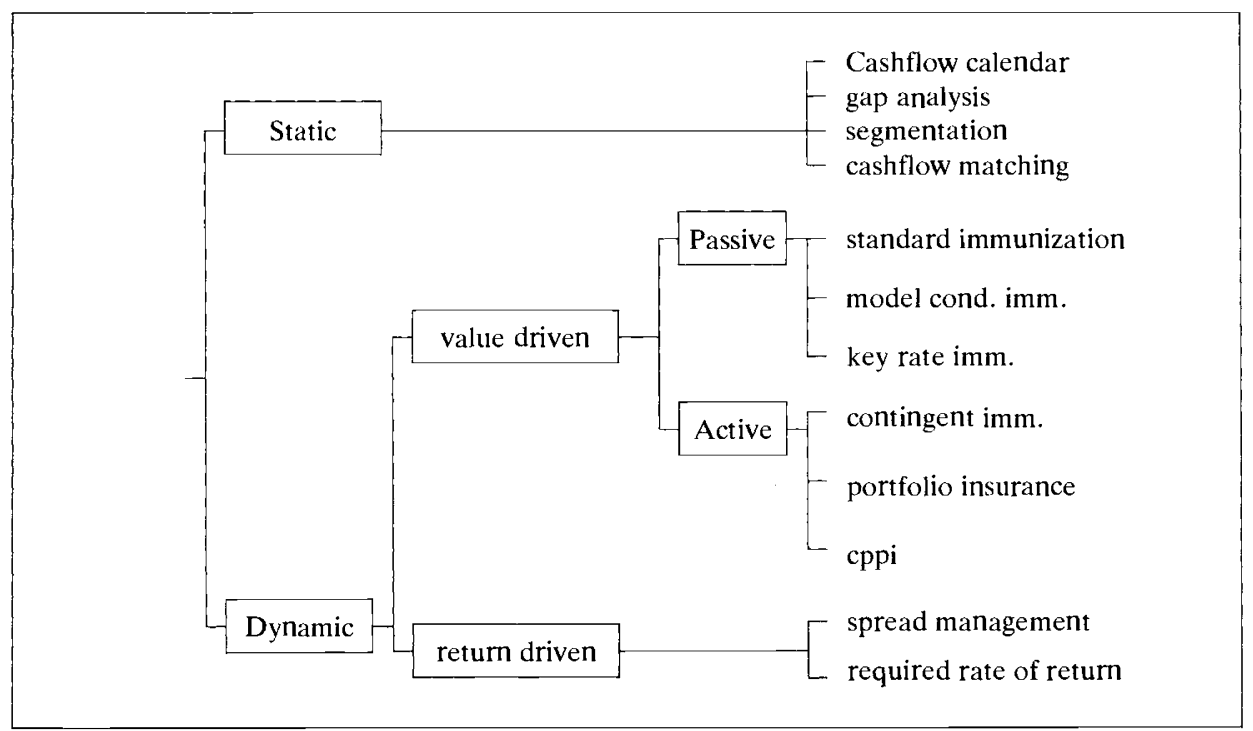

\section{Static techniques}

The static techniques mentioned here are, ranked at increasing level of sophistication required, cashflow payment calendars, gap analysis, segmentation of assets and liabilities, and cashflow matching. Most of these methods have found common application in banking and insurance, what may be explained by the fact that they are relatively simple and easy to use. All these techniques focus on a complete match between assets and liabilities, what is especially true in case of cashflow matching. As will be clear from their descriptions, since these techniques are both static and provide only a one-dimensional perspective on the assets and liabilities, they all lack the possibility of a consistent trade-off between risk and return. Neither risk nor return are explicitly measured by any of these techniques.

\section{- Cashflow payment calendars}

The cashflow payment calendar presents a maturity overview of all cash inflows and outflows. It is a tool for detecting major imbalances between cashflows resulting from assets and liabilities.

\section{- Gap analysis}

Gap analysis originates in the literature on bank Asset-Liability Management. Clifford (1981) defines the Gap as the balance sheet value difference between fixed and variable rate asset and liabilities. A non-zero Gap implies interest rate exposure. For instance, when there are more variable rate assets than liabilities, then a decline in rates will result in a loss in net operating income. Additionally, Gap analysis may be refined in order to account for maturity differences between assets and liabilities. 


\section{- Segmentation}

With segmentation liabilities are partitioned according to differences resulting from product characteristics. Additionally, each segment obtains an identifiable asset portfolio, tailored to meet the particular characteristics of the liabilities. ${ }^{3}$

\section{- Cashflow matching}

Cashflow matching aims to minimize the imbalances between all asset and liability cashflows, usually by means of linear programming. From an asset universe, a portfolio is selected which meets all liability payments with certainty, within a minimal acceptable time span, and with minimal cost ${ }^{4}$ It may be noticed that in contrast to the other three techniques, which are descriptive, this is predominantly a prescriptive technique.

Cashflow matching may lead to a number of practical problems. First, a complete match may not always be available in the market, e.g. when liability cashflows are of very long maturities and matching assets are not available in the market. As a result the programming problem which needs to be solved under the cashflow matching technique may prove to be infeasable. Second, a complete matching requirement may be too restrictive for portfolio management in that it does not allow for strategies which combine a higher degree of risk with a higher return. This is particularly true for those situations in which liabilities are priced relatively expensive and a complete matching approach does not allow for all the costs associated with the liabilities to be earned back on the asset portfolio. Thirdly, these techniques assume complete and accurate knowledge of the timing of all cashflows, which is often not available. ${ }^{5}$ Finally, related to the previously mentioned problem, difficulties may arise from the possible non-constant character of the cashflows. For instance, when cashflows are related to interest rates or are otherwise related to some stochastic factor, e.g. insurance claims, it may not be possible to be cashflow matched under all possible future scenarios.

\section{Multiscenario analysis}

Multiscenario analysis is intended to provide a link between the previously mentioned static techniques and completely dynamic strategies. ${ }^{6}$ The multiscenario technique is still static in nature, but it is possible also to formulate scenario contingent actions. Multiscenario analysis projects the development of the cashflows of the liability and the asset portfolios. These projections are made under different assumptions regarding future deve-

\footnotetext{
${ }^{3}$ Further discussion and a definition of segmentation can be found in: Attwood J. and Ohman C.: "Segmentation of Insurance Company General Accounts", Georgia Life Office Management Association, Inc., 1984

4 This assumption may be weakened such that interest income from reinvestments is allowed for and a low reinvestment risk is incurred, see for instance Fabozzi, Tong and Zhu (1989) or Dert and Rinnooy Kan (1991). This is sometimes referred to as dedication.

5 This is not only true for the liability portfolio but also for the asset portfolio. Strictly, bonds with call provisions or with the possibility of default are not included in the universe of investable assets for this technique.

${ }^{6}$ For frameworks that complete this link in case of a simple binomial lattice interest rate model, see: Ho, T.S. Y.: "Managing Illiquid Bonds and their linear Path Space", Global Advanced Technology Corp., (Sept. 1991), or the return driven strategy of Miller, Rajan and Shimpi (1989).
} 
lopment of a number of key variables, e. g. interest rates, inflation, etc. The analysis shows under which scenarios cashflows are not matched and what the consequences are for the overall organization. ${ }^{7}$ Also, it still focuses on flows instead of values.

Multiscenario analysis facilitates the modelling of complex relationships and allows for a multi dimensional risk concept. However, the multiscenarios and different dimensions of risk also create the core of potential problems associated with this technique. The user is likely to be biased towards particular scenarios which are considered to be more likely, where other scenarios may lead to the most serious distress. This may still be true when so called randomly generated scenarios are created. Furthermore, even though multiscenario analysis may lead to problem detection in a more general way than single scenario or static analysis, multiscenario analysis by itself does not provide an easy tool for management unless objectives, restrictions and their relative importances are clearly specified.

\section{Value driven dynamic strategies}

\subsection{Passive immunization strategies: surplus preservation ${ }^{8}$}

The basic idea underlying all immunization type strategies was formulated by Macaulay (1938). Macaulay derived a measure to represent the time element of assets and liabilities, the Macaulay duration. Analogy with the elasticity concept from economics, led to the definition of the modified Macaulay duration, which measures the interest rate sensitivity of the value of fixed cashflow assets or liabilities. From this, Redington (1952) formulated a strategy for maintaining the net value, or surplus, of a portfolio consisting of assets and liabilities with fixed cashflows, so called immunization.

Hereafter, a great deal of research has been done on immunization. ${ }^{9}$ Pitfalls have been detected and solutions have been provided in a number of cases. Here we will discuss the following immunization types of strategies: standard immunization, model conditioned immunization and key rate immunization. These strategies have the same objective: dynamical replication of a risk free asset, i. e. preservation of the surplus value.

\section{- Standard immunization}

Standard immunization implies matching of the interest sensitivities of assets and liabilities. In mathematical terms this requires equation of the first order partial derivatives of their valuation functions with respect to the yielding interest rate. Moreover the corresponding second order partial derivative of the assets is restricted to be at least as large as that of the liabilities. For fixed coupon assets, the first order partial

${ }^{7}$ For examples of multiscenario models, sce for instance: Winklevoss H. E.: "Plasm: Pension Liability and Asset Simulation Model", Journal of Finance, Vol. 37, No. 2 (1982), 585-594. Daykin C. D.: "Managing Uncertainty in a General Insurance Company", Journal of the Institute of Actuaries, Vol. 117 (1990), 173-259. Wilkie A. D.: "A Stochastic Investment Model for Actuarial Use", Transactions of the Faculty of Actuaries, Vol. 39, (1986), 341-373.

${ }^{8}$ Although the discussion is mainly directed to nominal, onc currency, interest rate immunization, it is entirely conceivable to apply these concepts to real interest rates, given the availability of inflation index-linked securities, and to international asset-liability portfolios. For multicurrency portfolios, the correct strategy requires immunization separately for each currency.

${ }^{9}$ Bierwag G.O., Kaufman G.C. and Khang C.: "Duration and Bond Portfolio Analysis: An Overview", Journal of Financial and Quantitative Analysis, 13 (1978), 671-685, and Bierwag G. O. (1987). 
derivative divided by the initial value, is known as modified Macaulay duration, while the relative second order derivative is now generally denoted with the term convexity. Where duration measures the point interest rate sensitivity of the asset or liability value, convexity measures the change in this duration as a result of changing interest rates. Matching asset and liability durations implies that the initial change in value of the asset and liability are of the same magnitude and direction. However, this will only be true for infinitely small changes in the flat term structure interest rate and for a small instant of time. ${ }^{10}$ Therefore, immunization requires continuous rebalancing of the portfolios and is explicitly a dynamic strategy. Creating and maintaining an asset portfolio with a larger convexity than that of the liability portfolio, implies that the change in value of the asset will be such that it will never be outperformed by the value change of the liability. The result being that the net value of assets minus liabilities will not decrease. ${ }^{11}$

The concept of convexity and its implications also point to the major weakness of standard immunization: the assumption of a flat term structure. If it is possible to be immunized with asset convexity in excess of liability convexity, then, given this assumption, it seems that any interest rate change would produce value from nothing. This would violate the basic no arbitrage proposition from financial theory.

In real-world term structure environments, however, this apparent arbitrage gain is predominantly the result of a risk-return trade-off. This will be clear when we note how differences in convexity come to exist. Convexity increases with the degree of dispersion of cashflows. Until now only one interest rate has been considered. In general the interest rates earned on assets and liabilities will differ for different maturities and depend on the so called term structure of interest rates. Assuming that there is only one relevant interest rate, as is the case with standard immunization, implies that results are only valid when parallel shifts in this term structure are considered. ${ }^{12}$ However, in reality non-parallel shifts are also relevant ${ }^{13}$ and the impact of non-parallel shifts on the value of the asset and liability portfolio will increase with convexity, ${ }^{14}$ also term structure risk increases with convexity. ${ }^{15}$

${ }^{10}$ More precise, as Cox, Ingersoll and Ross (1979) demonstrate, the Macaulay duration is only valid for interest rate dynamics described by Brownian motion.

${ }^{11}$ A discussion on the assumptions and derivations of immunization theory can be found in Granito (1984).

12 This assumption has been generalized by Fisher and Weil (1971) to cope with all possible initial term structures and all shape preserving shifts.

13 An idea of the relevance of non-parallel shifts may be obtained from the 1946-1987 term structure data in: Shiller R. J. and McCulloch J.H.: "The Term Structure of Interest Rates", National Bureau of Economic Research, working paper No. 234l (1987).

14 This has led to the devclopment of new risk concepts, e.g. Bierwag G. O., Kaufman G. C. and Toevs A.: "Bond Portfolio Immunization and Stochastic Process Risk", Journal of Bank Research 13, No. 4 (1983), 282-291 and Fong H. G. and Vasicek O.: "A Risk Minimizing Strategy for Portfolio Immunization", Journal of Finance, Vol. 34, No. 5 (1984), 1541 -1546.

${ }^{15}$ In addition to the increased risk, one might argue that increasing convexity will increase the amount of portfolio rebalancing required, and also increase the cost of the strategy because of transaction costs. See e.g.: Maloney K.J. and Logue D.E.: "Neglected Complexities in Structured Bond Portfolios", The Journal of Portfolio Management, (Winter 1989), 59-68. 
In addition to the problems caused by non-parallel shifts in the term structure, it should be noticed that modified Macaulay durations explicitly assume constant cashflows and therefore in general cannot meaningfully be applied to those cases where cashflows may be interest rate dependent. This is particularly true for assets and liabilities with prepayment options or interest rate sensitive coupon payments. Furthermore, as is true for all dynamic strategies, the performance of the strategy will depend on liquidity of the assets involved.

\section{- Model conditioned immunization}

To allow for more sophisticated term in structure changes some modifications to the standard immunization strategy have been developed. These modifications are conditional on assumptions regarding the stochastic process governing the development of the term structure. The resulting immunization strategies differ only in the duration and convexity measures used, not in operational respects.

\section{* Single factor immunization}

The simplest model conditioned immunization strategy uses the version of the theory on the long term structure of interest rates as formulated by Cox, Ingersoll and Ross (1985), with only the short term interest rate as a single stochastic factor determining bond prices. Given their assumptions on the term structure, the sensitivity of bond prices, for term structure shifts caused by the short term interest rate, can be represented by a model specific duration. ${ }^{16}$ Alternative specifications for the term structure process will lead to different duration measures. However, once the appropriate duration measure is derived, an immunization strategy similar to standard immunization results.

\section{* Multi-factor immunization}

Already implied in term structure model of Cox, Ingersoll and Ross is an extension of the single factor model to multi-factor models. The term multi-factor model indicates that a limited number of independent variables generate the bond price returns and thereby imply the shape of the term structure. The factors in the models based on the Cox, Ingersoll and Ross model, are usually linked to theoretical parameters, ${ }^{17} \mathrm{e}$.g. the long term average of the short term rate or interest rate volatility. Other factors, for instance those in the bond pricing model of Heath, Jarrow and Morton (1991) are based on observed forward rates and rely on statistical identification. Given the determined factors, strategies that immunize the portfolio for changes in these factors can be formulated.

The advantage of the model conditioned strategies is their potential accuracy and the opportunity to incorporate derivative instruments in the same term structure environment. The major disadvantage is the non-stationarity of factors, which incurs risk related to the validity of the model and requires monitoring to detect this non-stationairy bahaviour. In general, although the model conditioned strategies are theoretically superior to standard immunization, the advantage in practical applications is arguable. ${ }^{18}$

${ }^{16}$ Cox, Ingersoll and Ross (1979) denote this duration as stochastic duration.

${ }_{17}$ E.g. Brennan M.J., and Schwartz E.S.: "A Continuous Time Approach to the Pricing of Bonds", Journal of Banking and Finance, Vol. 3 (1979), 133-155. Fong H. Gifford and Vasicek O. A. : "Fixed-Income Volatility Management", The Journal of Portfolio Management, (Summer 1991), 41 - 46.

18 See e.g. Bierwag (1987). 
A significant development related to term structure modelling is the concept of effective duration. Effective duration ${ }^{19}$ measures the price sensitivity of assets or liabilities with embedded option elements. It generalizes the modified Macauly duration into a price elasticity that can be used for a complete bond universe. However, although the concept is generally applicable, the estimation of effective durations is critically determined by the assumptions underlying the term structure model used.

- Key rate immunization

Key rate immunization, as developed by Ho (1990) and Reitano $(1990,1991)$ is highly similar to standard immunization except that it explicitly recognizes the possibility of non-parallel term structure shifts. The solution to this provided by the key rate immunization strategy is segmentation of the cashflows. It is assumed here that the shape of the term structure is predominantly caused by a limited number of pivotal or key interest rates, from which the other values are obtained through interpolation. Similar to the case of standard immunization, additional assumptions regarding key interest rate behaviour may lead to estimation of effective (key rate) durations.

Key rate immunization may be regarded as a trade-off between standard immunization and complete cashflow matching. It provides more accuracy than the first and is more flexible and less restrictive than the latter. The main advantage over model conditioned strategies is its model independent character. Compared to standard immunization, it requires more sophistication.

* Active immunization strategies: floor protection

The active immunization strategies aim to guarantee a minimally acceptable floor value for the asset portfolio. For Asset-Liability purposes, this floor is determined by the end of period value of the liabilities. Discussed here are contingent immunization, portfolio insurance, constant proportion portfolio insurance and other value protecting strategies using options. Except for contingent immunization these strategies were originally designed for equity portfolios, especially the last two strategies may be applied to bond portfolio management also.

\section{- Contingent immunization}

Contingent immunization is a technique developed by Leibowitz and Weinberger $(1982,1983)$ which combines the possibility of active portfolio management with the requirements of portfolio matching. The basic idea is that an asset portfolio can be immunized at any moment in time, but as long as the portfolio has sufficient value to meet the liabilities, it can be managed actively with the objective of achieving outperformance. However, should the portfolio value decline to a previously specified minimum value, the immunization mode is triggered and the portfolio is managed through an immunization strategy.

\section{- Portfolio insurance}

Based on option pricing theory and the derivation of the Black-Scholes option pricing formula, ${ }^{20}$ Leland and Rubinstein (1981) developed a strategy using stocks and bonds, which allows for the upside potential resulting from stock investments, but maintains

\footnotetext{
${ }^{19}$ See e. g. Douglas (1990).
}

${ }^{20}$ Black F., and Scholes M.: "The pricing of options and Corporate Liabilities", Journal of Political Economy, 81 (1973), 637-654. 
the portfolio value above or at a prespecified level. The rationale behind this strategy is based on synthetical creation of a put option on a stock portfolio, i. e. the strategy replicates the value of the put option.

Experience from the 1987 stock market crash has demonstrated the fragility of this synthetical strategy. The strategy crucially depends on market liquidity, which may be absent when the protective element of the strategy is most needed. In general the use of traded options on a stock portfolio will prove to be safer.

The option pricing approach does point to some interesting conclusions. In efficient markets a risk free match will, if available, provide no excess returns. Upward potential in returns - and thus in value - as well as downward protection, carry a cost. ${ }^{21}$

\section{- Constant Proportion Portfolio Insurance (CPPI)}

$\mathrm{CPPI}^{22}$ may be regarded as a combination of contingent immunization and portfolio insurance. It is similar to both strategies in that it specifies a minimal acceptable floor. Part of the total portfolio value, called the reserve account, is invested in a risk free asset or strategy and guarantees the value of the floor at the end of the investment period. The residual part of the total portfolio is called the active account. Part of this active account may be invested in a risky asset or portfolio. However, the proportion of the active account invested risky, is stable over time. ${ }^{23}$ While the reserve account grows over time to guarantee the floor, the active account provides upside potential.

The main differences between CPPI and synthetical portfolio insurance is the response to realized returns on the risky assets. Where portfolio insurance increases the exposure to the risky asset when this asset rises in value, CPPI holds on to same portfolio proportions and therefore may either increase or decrease the exposure, depending on the proportion value. ${ }^{24}$ Furthermore, the CPPI strategy is time invariant, i.e. the proportion of assets invested risky does not depend on time, in contrary to the portfolio insurance strategy. However, both strategies have their costs and are not capable of complete protection. ${ }^{25}$ An extension to the CPPI strategy, with adjusting floor levels, has been suggested by Crouhy (1991).

\section{- Other value protecting strategies using options}

Where synthetically created options may prove risky, this is not true for traded options. Pelsser and Vorst (1991) provide an interesting framework using options to structure a portfolio which meets several shortfall constraints. Although, as with portfolio insur-

21 Compare Bodie Z.: „Shortfall Risk and Pension Fund Asset Allocation”, Financial Analysts Journal, (May-June 1991), 57-61.

${ }^{22}$ See: Black F. and Jones R. (1987). Application to fixed income, see: Hakanoglu E., Kopprasch R. and Roman E.: "Constant Proportion Portfolio Insurance for Fixed-Income Investment", The Journal of Portfolio Management, (Summer 1989), 58-66.

${ }^{23}$ Which is consistent with particular cases of continuous time portfolio selection, see Merton R. C.: Optimum Consumption and Portfolio Rules in a Continuous Time Model", Journal of Economic Theory, 3 (1971), $373-413$.

${ }^{24}$ In this case, for the proportion of risky assets above 1, additional risky assets are acquired, below 1 risky assets are sold. The first situation implies leverage of the active account, and thus borrowing from the reserve account to the active account.

${ }^{25}$ For a comparison of both strategies, see: Zhu Y. and Kavee R. C.: "Performance of Portfolio Insurance Strategies", The Journal of Portfolio Management, (Spring 1988), 48-54. 
ance, assumptions are made regarding the stochastic behaviour of stocks, their article provides exemplary insight to what may be obtained with this type of portfolio structuring techniques.

It should be noticed that all these strategies more or less tacitly assume the availability of a positive surplus. This surplus is invested highly risky, when considered separately in an asset-only framework. Therefore, careful analysis regarding the benefits of these strategies is required, in order to determine their attractiveness on a risk-adjusted base.

\section{Return driven dynamic strategies}

More or less opposed to the immunization type strategies which focus on value, we have strategies which are mainly directed by returns or spreads. This often leads to a neglect of the value monitoring inherent in the immunization strategies. As a result, not all risk may be represented correctly.

\section{- Spread management}

Spread management focuses on maintaining a yield spread between the asset and liability portfolio. It is related to the idea of segmentation and a buy and hold investment strategy. Usually both asset and liability portfolio yields are related to term structure derived treasury bond yields.

The more sophisticated spread management not only considers the spread but relates differences in spreads to spread determining factors, e.g. duration differences, credit risk, thereby using concepts like option adjusted spread analysis and spread duration. ${ }^{26}$ Where the traditional spread management considers most nominal asset and liability values, it is clear that the Asset-Liability Management appropriate spread management is based on market values and should be incorporated into a broader risk-return framework.

\section{- Required rate of return analysis}

Required rate of return analysis as formulated by Miller, Rajan and Shimpi (1990) considers the future cashflows of the liabilities and calculates the return required on the current cashbalance of the liability to meet these cashflows. These returns are then used for selecting a particular asset portfolio. The selection may be contingent on a number of scenarios in combination with a risk criterion.

The main benefits arise from its relative simplicity and its ability to identify trading opportunities. The disadvantages are related to its stress on returns which may lead to non-identified risk acceptance, e.g. the higher returns are usually caused by additional credit or mismatch risk, which is not identified as such by the strategy.

${ }^{26}$ See e.g. Herskowitz M.D.: "Option Adjusted Spread Analysis for Mortgage-Backed Securities", Chapter 22 in: Fabozzi F.J. (ed.): Handbook of Fixed Income Options, Probus Publishing Cy, Chicago, 1989, and Leibowitz M. L., Krasker W. S. and Nozari A. N.: "Spread-Duration: A New Tool in Bond Portfolio Management", Chapter 13 in: Fabozzi F. J. (ed.): Fixed Income Portfolio Strategies, Probus Publishing Cy, Chicago, 1989. 


\section{Risk-return analysis}

Largely based on the ideas of Markowitz (1952) and the further development of the Capital Asset Pricing Model (CAPM) ${ }^{27}$ and Arbitrage Pricing Theory (ATP), ${ }^{28}$ risk-return analysis has become a major device for investment analysis. Risk-return analysis is the most general theoretical framework for this type of decision making. ${ }^{29}$

The basic principle is that when two portfolios with assets and liabilities have different expected returns, they either have different risk - such that the higher return portfolio also has a higher risk - or one of the portfolios is not efficient ${ }^{30}$ From all possible portfolios, the rational investor will only consider efficient portfolios and chooses the one that has the most attractive risk-return trade-off, given the risk-return preference of the investor.

Wise (1984a, b), Wilkie (1984) and later Leibowitz and Langeteig (1991) apply the portfolio selection principles in general setting to the matching of assets and liabilities, considering ultimate surplus as key variable. Furthermore, there are an increasing number of applications of risk-return analysis in combination with some of the previously described techniques or strategies. ${ }^{31}$

Although risk-return analysis is a very useful and generally applicable concept, care must be taken with selection of the input variables: risk and return. When ill defined, or based only on often non-stationary historical data the risk-return framework may tend to magnify errors.

\section{Criteria for evaluating techniques and strategies}

It is difficult to evaluate the many different techniques and strategies on the basis of a single criterion. Each strategy or technique has potential advantages and disadvantages and may fulfil a particular need for Asset-Liability Management purposes. However, we may formulate a few criteria which are relevant to all.

${ }^{27}$ See: Lintner J.: "The Valuation of Risky Assets and the Selection of Risky Investments in Stock Portfolios and Capital Budgets", Review of Economics and Statistics, 47 (1965), 13-37. Mossin J.: "Equilibrium in a Capital Asset Market", Econometrica, 34 (1966), 768-783. Sharpe W. F.: "Capital Asset Prices: A Theory of Market Equilibrium under Conditions of Risk", Journal of Finance, 19 (1964), 425-442.

${ }^{28}$ See: Ross S.A.: "The Arbitrage Theory of Capital Asset Pricing", Journal of Economic Theory, 13 (1976), $341-360$.

29 Although in many applications risk-rcturn analysis is performed using variance or standard deviation as a risk measure, this is not necessarily so. Many approaches using different risk measures have been developed, e. g.: Baumol W. J.: "An Expected Gain Confidence Limit Criterion for Portfolio Selection", Management Science, (October 1963). Fishburn P. C.: "Mean-Risk Analysis with Risk Associated with Below-Target Returns", American Economic Review, Vol. 67, No. 2 (March 1977), 116-124. Harlow W. V. and Rao R. K. S.: "Asset Pricing in a Generalized Mean-Lower Partial Moment Framework: Theory and Evidence", Journal of Financial and Quantitative Analysis, Vol. 24, No. 3, (1989), 285-311. Brodt A. L.: "MIN-MAD Life: A Multi-Period Optimization Model for Life Insurance Company Investınent Decisions", Insurance : Mathematics and Economics, 2 (1983), 91 - 102.

30 The other portfolio has a higher return given a particular level of risk, a higher risk given a return level or lower return and higher risk.

${ }^{31}$ Risk-return analysis in combination with multi-scenario analysis, e. g. Coutts S. M. and Clark G.J.: "A Stochastic Approach to the Allocation of Assets for Financial Institutions", unpublished, 1991. Risk-return analysis in combination with duration strategy, e. g. Bierwag (1987). 
Table 1:

Technique :

Completeness
Return Risk

Observability

Model

Data

Independence Requirement

- Cashflow payment calendars

- Gap analysis

- Segmentation

- Cashflow matching

- Multi scenario analysis

Risk

+
+
+
+

$\begin{array}{ll}+ & + \\ + & + \\ + & + \\ + & 0\end{array}$

0

0

0

Strategy:

- standard immunization

- model conditioned immunization

* single factor

* multi factor

- key rate immunization

- contingent immunization

- portfolio insurance

- c.p.p.i.

- protecting strategies

- realized rate of return

- spread management

- risk-return analysis

Legenda:

strength +

weakness -

neutral

$\begin{array}{ll}0 & 0 \\ 0 & 0 \\ 0 & + \\ 0 & + \\ + & 0 \\ + & 0 \\ + & 0 \\ + & + \\ + & 0 \\ + & - \\ + & +\end{array}$

+
0
-
+
+
0
+
0
0
+
0

$\begin{array}{ll}+ & + \\ - & - \\ - & - \\ + & - \\ 0 & 0 \\ - & \\ - & \\ 0 & \\ + & - \\ + & \\ + & \end{array}$

First, we may consider the completeness of the technique or strategy, consisting of:

- return completeness: are all potential return opportunities unambiguously representable, and

- risk completeness: are all risks reflected consistently.

Although the costs of technique or strategy and tax effects are often neglected in theoretical derivations, the appropriate risk and return, are those that include all associated costs. ${ }^{32}$

32 These costs do not only consist of transaction and management costs, there may also be significant efficiency losses associated with a particular strategy. For examples on this and a theoretical framework for assessing the costs of a strategy, see: Dybvig, P. H.: "Inefficient Dynamic Portfolio Strategies or How to Throw Away a Million Dollars in the Stock Market", The Review of Financial Studies, Vol. 1, No. 1 (1988), 67-88. 
The importance of these completeness criteria follows from their use for asset-liability decision making. Comparison of different alternatives can only be meaningful when the expected results from these alternatives are measured similarly.

In addition to these basic criteria, we may formulate three criteria which determine the level of use and their practicality:

- observability:

- model independence: are all variables aggregate and measurable, ${ }^{33}$ the technique or strategy is model independent when the character and reliability of the technique or strategy is not significantly determined by the theoretical assumptions, and

- data requirements : the amount of data and knowledge needed for successful implementation of the strategy or technique.

In general we may prefer a technique or strategy that is both return and risk complete and has the highest degree of observability and model independence. In reality, the presented techniques and strategies do not meet all criteria. For instance, risk-return analysis may both be return and risk complete, it may also have a high degree of model independence but it is usually not very observable. On the other hand, cashflow matching of fixed liabilities may be highly observable, but is not return and risk complete, i. e. it does not facilitate comparison with more risky alternatives.

The impact of the observability and model independence criteria is most significant when different levels in the Asset-Liability Management process are recognized. Each level of decision making may emphasize different aspects of the technique or strategy. Considering the strategic level of decision making, where overall benchmarks for the asset and liability portfolios are formulated, we may want to use strategies or techniques with a high degree of observability and model independence. Once overall asset liability portfolio objectives and management constraints are determined, less observable and more model dependent strategies may be used for tactical portfolio management in order to achieve greater performance.

Data requirements and required technical knowledge needed for executing a particular strategy or technique are largest for the most advanced strategies and techniques. Moreover, the impact of the quality of inputs on successful implementation, is usually stronger the more advanced the strategy is.

Considering these criteria we may make the following general statements regarding the various techniques and strategies.

- The static techniques nearly all lack risk and return completeness. They mainly focus on only one aspect of the asset-liability portfolio and do not allow for statements regarding the importance and the severity of imbalances, of this particular aspect.

- The passive immunization strategies provide greater depth regarding the risks of duration mismatches. However, unless they are embedded in a risk-return framework, no statement regarding the potential benefits and returns from accepting these imbalances can be made. Additional detail on risk has a cost in terms of observability and model independence, although in case of standard immunization, this cost is probably relatively small.

${ }_{33}$ E. g. prices are more observable than yields, bond yields are more observable than expected returns on equities. 
- The active immunization strategies add considerably more detail on potential returns than the passive strategies, but also have a cost in terms of risk completeness, observability and model independence.

Table $1^{34}$ summarizes the different techniques and strategies with regard to the four criteria. It is clear that there is not a single dominating technique or strategy.

\section{Summary and conclusions}

In recent years a great number of techniques and strategies have been developed which are useful for Asset-Liability Management. These techniques and strategies have been developed for different purposes and have different benefits and disadvantages. The most important techniques and strategies were discussed here in three distinct categories: 1) static, 2) value driven, and 3) return driven. The techniques and strategies discussed are summarized in Figure 1. Furthermore, attention has been paid to multiscenario analysis and risk-return analysis.

In addition, a number of criteria has been suggested in order to evaluate the usefulness of the different techniques and strategies. This is especially relevant when different phases in the Asset-Liability Management process are distinguished. There is not a dominating technique or strategy and therefore different methods may be used simultaneously.

\footnotetext{
34 The symbols should be interpreted in a relative sense, for instance: the + for model independence of standard immunization means that standard immunization has a high degree of model independence relative to the other strategies, not that it is model independent in an absolute sense.
}

\section{REFERENCES}

BIERWAG, G. O.: Duration analysis: Managing Interest Rate Risk, Ballinger Publishing Company, Cambridge, Massachusetts, 1987.

BLACK, F. and JONES, R.: "Simplifying Portfolio Insurance", The Journal of Portfolio Management, (Fall 1987), 48-51.

CLIFFORD, J. T.: "A Perspective on Asset-Liability Management: Part I", in: Bank Management, Brick, J. R., editor, R. F. Dame Inc., Richmond, Virginia, 1981.

COX, J.C., INGERSOLL, J.E. and ROSS, S. A.: "Duration and the Measurement of Basis Risk", Journal of Business, Vol. 52, No. I (1979), 51-61.

COX, J.C., INGERSOLL, J.E. and ROSS, S. A.: "A Theory of the Term Structure of Interest Rates", Econometrica, 53 (1985), 385-407. 
CROUHY, M.: "Dynamic Ratchet: A Portfolio Management Strategy to Trade Volatility", Paper presented at the Inquire Seminar, Rome (1991).

DERT, C.L. and RINNOOY KAN A.H.: "Fixed Income Asset Liability Management", proceedings 2nd AFIR International Conference, Vol. 3, (1991), 285-299.

DOUGLAS, L. C.: Bond Risk Analysis, New York Institute of Finance, Simon and Schuster Inc, New York, 1990.

FABOZZI, T. D., TONG, T. and ZHU, Y.: "Beyond Cash Matching", in: Advances in Bond Analysis and Portfolio Strategies, Fabozzi F. J. and Garlicki T. D., editors, Probus Publishing, Chicago, Illinois, 1989.

FISHER, L. and WEIL, R. L.: "Coping with the Risk of Interest Rate Fluctuations: Returns to Bondholders from Naive and Optimal Strategies", Journal of Business, (October 1971), 408-431.

GRANITO, M. R.: Bond Portfolio Immunization. Toronto, D. C. Heath and Company, 1984.

HEATH, D., JARROW, R. and MORTON, A.: "Bond Pricing and the Term Structure of Interest Rates: A New Methodology for Contingent Claims Valuation“, Econometrica, 1991.

HO, T. S. Y.: Strategic Fixed Income Investment. Homewood, Ill., Dow Jones-Irwinn, 1990.

LEIBOWITZ, M. L. and LANGETEIG, T. C.: "Asset Allocation under Shortfall Constraints", The Journal of Portfolio Management, (Winter 1991), 18-23.

LEIBOWITZ, M. L. and WEINBERGER, A.: "Contingent Immunization - Part I: Risk Control Procedures", Financial Analysts Journal, (November-December 1982), 17-31.

LEIBOWITZ, M. L. and WEINBERGER, A.: "Contingent Immunization - Part II : Problem Areas", Financial Analysts Journal, (January-February 1983), 35-50.

LELAND, H. and RUBINSTEIN, M.: "Replicating Options with Position in Stock and Cash", Financial Analysts Journal, (July-August 1981), 63-72.

MACAULAY, F. R.: Some Theoretical Problems Suggested by the Movements of Interest Rates, Bond Yields, and Stock Prices in the U.S. Since I856. New York, National Bureau of Economic Research, 1938.

MARKOWITZ, H. M.: "Portfolio Selection", The Journal of Finance, Vol. 7, No. 1 (1952), 77-91

MILLER, L., RAJAN, U. and SHIMPI, P. A.: "Realized Return Optimization : A Strategy for Targeted Total Return Investing in the Fixed Income Markets", in: The Institutional Investor Focus on Investment Management, edited by Fabozzi, F. J., Ballinger Publishing, 1989.

PELSSER, A. and VORST, A. C. F.: "Optimal optioned portfolios with confidence limits on shortfall constraints", unpublished manuscript, Erasmus University Rotterdam, 1991.

REDINGTON, F. M.: "Review of the Principle of Life Office Valuations", Journal of the Institute of Actuaries, 18 (1952), 286-340.

REITANO, R. R.: "Multivariate Duration Analysis", Transactions of the Society of Actuaries, Vol. XLIII (1991).

REITANO, R. R.: "Non-Parallel Yield Curve Shifts and Durational Leverage", The Journal of Portfolio Management, (Summer 1990), 62-67.

WILKIE, A. D.: "Portfolio Selection in the Presence of Fixed Liabilities: A Comment on 'The Matching of Assets to Liabilities", Journal of the Institute of Actuaries, 111 (1984), 229-277.

WISE, A. J.: "A Theoretical Analysis of the Matching of Assets to Liabilities", Journal of the Institute of Actuaries, 111 (1984a), 375-402.

WISE, A. J.: "The Matching of Assets to Liabilities", Journal of the Institute of Actuaries, 111 (1984b), 445-485. 